\title{
Design and Development of a Centrifugal Atomizer for Producing Zinc Metal Powder
}

\author{
Phairote Sungkhaphaitoon, Thawatchai Plookphol, and Sirikul Wisutmethangoon
}

\begin{abstract}
In the present work a preliminary design of a centrifugal atomizer for producing zinc metal powder was studied. In the design process, the consumed power and the atomizing disc size were first estimated. The trajectory of flying melt droplet from the edge of atomizer disc and the temperature profile were predicted using a concept of heat transfer in an external flow for calculating the size of atomizer chamber. A simple laboratory-scale atomizer was built. The performance of the atomizer was studied by using pure zinc metal as a model material. The effects of rotating disc speed on median particle size, particle size distribution and standard deviation, production yield, and morphology of the atomized zinc powder were investigated. The atomization was carried out using graphite flat disc, melt pouring temperature, preheating disc temperature and melt feed rate of $40 \mathrm{~mm}, 550{ }^{\circ} \mathrm{C}, 300{ }^{\circ} \mathrm{C}$ and 50 $\mathrm{kg} / \mathrm{h}$, respectively. The atomizer disc speeds were varied from 10,000 to $30,000 \mathrm{rpm}$. It was evidenced from the experimental results that the median particle size and standard deviation of zinc metal powder decreased with increasing disc speed. The production yield tended to increase with increasing rotating speed. SEM images revealed that most zinc metal particles were irregular, elongated flakes. The produced zinc power in this study may be suitable for use as a friction material for manufacturing brake pad in the automotive part industry.
\end{abstract}

Index Terms-Centrifugal atomization; design process; particle size distribution; zinc metal powder.

\section{INTRODUCTION}

Centrifugal atomization of melt has been used for metal powder production for decades. This process is able to produce metal powders with spherical shape, less impurity, high production yield and narrow size distribution. Moreover, the production cost of this process is lower comparing to water or gas atomization because of its lower energy consumption [1]. Centrifugal atomization has been successfully applied for processing many kinds of metal powders such as $\mathrm{Sn}, \mathrm{Pb}, \mathrm{Al}, \mathrm{Mg}, \mathrm{Zn}, \mathrm{Ti}, \mathrm{Ni}, \mathrm{Co}$ and their alloys [1]-[3]. For zinc metal powder, it can be produced by air, water or centrifugal atomization process. However air and water atomization consumes higher energy and leads to

Manuscript received February 23, 2012; revised March 24, 2012. This work was supported in part by the Department of Mining and Materials Engineering, Faculty of Engineering and the Graduate School, Prince of Songkla University, Hat Yai 90112, Thailand.

P. Sungkhaphaitoon is with the Department of Mining and Materials Engineering, Faculty of Engineering, Prince of Songkla University, Hat Yai 90112, Thailand (jeen_mat@hotmail.com).

T. Plookphol is with the Department of Mining and Materials Engineering, Faculty of Engineering, Prince of Songkla University, Hat Yai 90112, Thailand (thawatchai.p@psu.ac.th).

S. Wisutmethangoon is with the Department of Mechanical Engineering, Faculty of Engineering, Prince of Songkla University, Hat Yai 90112, Thailand (sirikul@me.psu.ac.th). higher operating cost [4]. Zinc metal powder has wide applications such as alkaline batteries, galvanizing and chemical industry [5], [6]. It is used as a friction material for brake pad in the automotive part industry as well. The development of centrifugal atomization process for producing zinc metal powder with a lower production cost is drawn into our research interest. The present work was aimed at a preliminary design and construction of a centrifugal atomizer for producing zinc metal powder. The performance of the atomizer was tested by studying the effect of angular speed on median particle size, particle size distribution, production yield, and morphology of the atomized zinc metal powder.

In centrifugal atomization, it is necessary to conceive the basics of metal droplet formations by centrifugal force. Theoretically, molten metal stream is poured directly onto an atomizer disc spinning at a high angular speed. The molten metal forms a thin film on the surface of the disc, breaks up to small droplets and solidifies into particles [7]. The atomization can be occurred in three typical modes: direct drop formation (DDF), ligament disintegration (LD) and film disintegration (FD) which is dependent upon the process parameters and resulted in metal powder with different size and morphology [8], [9]. Droplet diameter $(D)$ of particulate metal can be predicted by Eq (1) [1].

$$
D=\sqrt{\frac{A \gamma}{\rho \omega^{2} R}}
$$

where $A$ is a constant with the value of $6, \gamma$ is the surface tension $(\mathrm{N} / \mathrm{m}), \rho$ is the density $\left(\mathrm{kg} / \mathrm{m}^{3}\right), \omega$ is the angular speed $(\mathrm{rad} / \mathrm{s})$ and $R$ is the atomizer disc radius (m). The droplet diameter was found to be correlated to the rotating speed, the atomizer disc radius and some physical properties of atomized material. It is noted from Eq (1) that with increasing angular speed will result in smaller droplet size.

\section{A. Preliminary Design}

In a preliminary design of centrifugal atomization, one should consider a rotational speed of atomizer and power consumption for the appropriate selection of the electric motor, the atomizer disc and chamber sizes.

\section{B. Consumed Power}

The consumed power $(W)$ used in atomization process with respect to melt flow rate, surface tension of melt, mean droplets diameter and energy efficiency can be estimated from $\mathrm{Eq}(2)$ [10].

$$
W=\frac{6 \gamma Q}{\eta d_{50}}
$$


where $\gamma$ is the surface tension of liquid metal $(\mathrm{N} / \mathrm{m}), Q$ is the volume flow rate of the liquid metal $\left(\mathrm{m}^{3} / \mathrm{s}\right), d_{50}$ is the mean droplets diameter $(\mu \mathrm{m})$ and $\eta$ is the energy efficiency of centrifugal atomization $(0.005)$. The surface tension of liquid zinc at $419.5^{\circ} \mathrm{C}$ is $0.714 \mathrm{~N} / \mathrm{m}$ [11]. According to Eq (2), to produce zinc powder having droplet diameter $\left(d_{50}\right)$ of 106 $\mu$ mat the melt flow rate of $50 \mathrm{~kg} / \mathrm{h}\left(Q=2.03 \times 10^{-6} \mathrm{~m}^{3} / \mathrm{s}\right)$, the minimum power required for atomization is $16 \mathrm{~W}$ whereas to produce the smaller droplet diameter of $25 \mu \mathrm{m}$, at the same melt flow rate, the required power is increased to $70 \mathrm{~W}$.

\section{Atomizer Disc}

For centrifugal atomization, the atomizer disc is the most important component because its size and shape are directly influenced on the median particle size of powder. Many previous works have been concentrated on the study of atomizer disc for different sizes and shapes. In this study, we have worked on flat disc atomizer since the theoretical and empirical models and experimental data have been widely reported. The maximum radius $(R)$ of atomizer disc can be calculated from Eq (3) [10].

$$
R=\frac{1}{\omega} \sqrt{\frac{2 W}{\rho Q}}
$$

where $\omega$ is the angular speed of atomizer disc $(\mathrm{rad} / \mathrm{s}), W$ is the power consumption (W), $\rho$ is the density of liquid metal $\left(\mathrm{kg} / \mathrm{m}^{3}\right)$ and $Q$ is the volume flow rate of liquid metal $\left(\mathrm{m}^{3} / \mathrm{s}\right)$. The molten zinc at temperature of $419.5^{\circ} \mathrm{C}$ has a density of $6,570 \mathrm{~kg} / \mathrm{m}^{3}$. To produce zinc powder with mean droplet diameters of $106 \mu \mathrm{m}$ and $25 \mu \mathrm{m}$ by using centrifugal atomizer at angular speed of 30,000 rpm $(\omega=3,141.59 \mathrm{rad} / \mathrm{s})$ and melt flow rate of $50 \mathrm{~kg} / \mathrm{h}\left(Q=2.03 \times 10^{-6} \mathrm{~m}^{3} / \mathrm{s}\right)$, the maximum atomizer disc radius of $0.015 \mathrm{~m}$ and $0.033 \mathrm{~m}$ are required respectively for atomization.

\section{Maximum Distance for Complete Solidification}

Although the principle of centrifugal for atomization application has been established for years, the parameters which were less mentioned are the ejection and the thermal history of flying droplet. Practically, the maximum distance of melt droplets needed to be completely solidified after setting off from the edge of atomizer disc is a significant parameter for designing an atomizer chamber size. In the present work, the trajectory of flying droplet and its temperature profile were studied by using a concept of liquid flow pass a body with heat transfer in an external flow which are demonstrated in the next paragraphs.

\section{E. Trajectory of Droplet}

Velocity of melt droplet is assumed to be equal to the speed of melt after it just detaches from the edge of atomizer disc. The flying distance of melt droplet can be estimated from a simple concept of projectile motion. However, the distance calculated from this concept only is too large because an effect of drag due to air viscosity is neglected. For more accurate estimation of the path distance of a single spherical droplet, the drag effect and heat transfer behavior of melt were employed to predict the maximum distance in order to avoid melt stick onto the chamber wall. The velocity of melt film on atomizer disc is divided into two components, the peripheral velocity and the radial velocity (Fig. 1). The velocity of melt depends on wettability of liquid on atomizer disc, geometry of atomizer disc and properties of melt. The velocity of melt $(V)$ at the edge of an atomizer disc can be estimated from Eq (4). [12]

$$
V=V_{T}+V_{R}
$$

where $V_{T}$ is the peripheral velocity $(\mathrm{m} / \mathrm{s})$ and $V_{R}$ is the radial velocity $(\mathrm{m} / \mathrm{s})$.

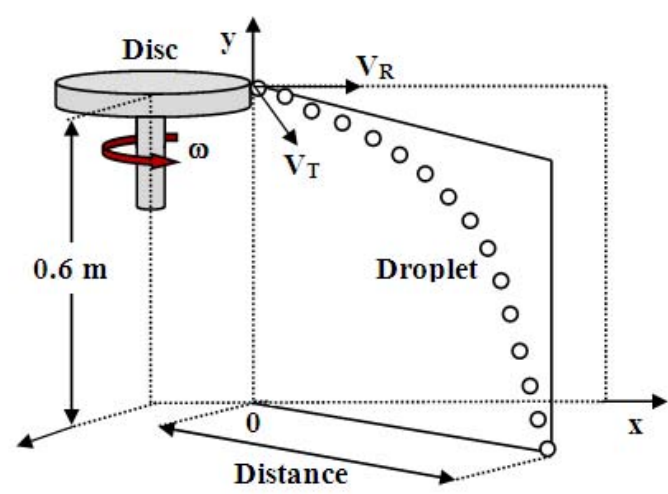

Fig. 1. Simple projectile motion of melt droplet detaching from the edge of atomizer disc [12].

The Reynolds number ( $\mathrm{Re})$ is calculated from the following expression [12].

$$
\mathrm{Re}=\frac{\rho_{a} V d}{\mu_{a}}
$$

where $\rho_{a}$ is the air density $\left(\mathrm{kg} / \mathrm{m}^{3}\right), V$ is the velocity of melt droplet at the edge of an atomizer disc $(\mathrm{m} / \mathrm{s}), d$ is the diameter of droplet (m) and $\mu_{a}$ is the air viscosity (Pa.s). Drag force due to the air viscosity exerts on a flying droplet is calculated from $\mathrm{Eq}(6)$ [13].

$$
f_{d}=-\frac{1}{2} r_{a} V^{2} A C_{d}
$$

where $f_{d}$ is the drag force $\left(\mathrm{kg} \mathrm{m} / \mathrm{s}^{2}\right), A$ is the area of a droplet particle $\left(\mathrm{m}^{2}\right)$ and $C_{d}$ is the drag coefficient which can be calculated from $\mathrm{Eq}(7)$ [12].

$$
\mathrm{C}_{\mathrm{d}}=\frac{24}{\operatorname{Re}}\left(1+\frac{\mathrm{Re}^{\frac{2}{3}}}{6}\right)
$$

where Re is the Reynolds number. This equation represents the drag coefficient expression for the Reynolds number between 65 and 300 [12]. Hence, the equation of motion in $\mathrm{x}$ and $y$-direction of a single droplet travelling along its path in an air atmosphere is shown in Eq (8) and Eq (9), respectively.

$$
\frac{d^{2} x}{{d t^{2}}^{2}}=-\frac{\rho_{a}\left(\frac{d x}{d t}\right)^{2} A C_{d}}{2 m_{d}}
$$

where $m_{d}$ is the mass of droplet $(\mathrm{kg})$ and $g$ is the acceleration 
due to gravity $\left(9.81 \mathrm{~m}^{2} / \mathrm{s}\right)$.

$$
\frac{d^{2} y}{d t^{2}}=g-\frac{\rho_{a}\left(\frac{d y}{d t}\right)^{2} A C_{d}}{2 m_{d}}
$$

\section{F. Heat Transfer Behavior of Droplet}

During the flight, a melt droplet transfers heat to the surrounding and solidifies. Generally, the thermal behavior of melt pending atomizing process is a complex one to figure out precisely. It was found that some heat transferred to the atmosphere inside the chamber and some lost during the formation of a droplet on the edge of atomizer disc. The average value of heat transferred from an ejected melt droplet is calculated from the sum of heat convection $\left(Q_{\text {conv }}\right)$ and heat radiation $\left(Q_{\mathrm{rad}}\right)$ using Eq (10) [14].

$$
\begin{gathered}
Q_{\text {ave }}=Q_{\text {conv }}+Q_{\text {rad }} \\
Q_{\text {ave }}=h A_{s}\left(T_{s}-T_{\text {surr }}\right)+\varepsilon \sigma A_{s}\left(T_{s}^{4}-T_{\text {surr }}^{4}\right)
\end{gathered}
$$

where $h$ is the convection heat transfer coefficient $\left(\mathrm{W} / \mathrm{m}^{2}{ }^{\circ} \mathrm{C}\right)$, $A_{s}$ is the total surface area of sphere particle $\left(\mathrm{m}^{2}\right), \varepsilon$ is the emissivity (0.05), $\sigma$ is the Stefan's constant $\left(5.67 \times 10^{-8}\right.$ $\left.\mathrm{W} / \mathrm{m}^{2} \cdot \mathrm{K}^{4}\right), T_{s}$ is the temperature of surface droplet $\left({ }^{\circ} \mathrm{C}\right)$ and $T_{\text {surr }}$ is the temperature of surrounding $\left({ }^{\circ} \mathrm{C}\right)$. The performance of heat convection from the ejected droplet to the surrounding is described in term of the dimensionless Nusselt number. The relationship between Reynolds Number (Re), Nusselt number $(\mathrm{Nu})$, and Prandtl number $(\mathrm{Pr})$ was proposed by Whitaker as shown in Eq (11) [14].

$$
N u=\frac{h D}{k}=2+\left[0.4 \operatorname{Re}^{1 / 2}+0.06 \operatorname{Re}^{2 / 3}\right] \operatorname{Pr}^{0.4}\left(\frac{\mu_{\infty}}{\mu_{s}}\right)^{1 / 4}
$$

where $D$ is the diameter of droplet $(\mathrm{m}), k$ is the thermal conductivity $\left(\mathrm{W} / \mathrm{m} .{ }^{\circ} \mathrm{C}\right), \mu_{\infty}$ is the dynamic viscosity of surroundings $\left(\mathrm{m}^{2} / \mathrm{s}\right)$ and $\mu_{s}$ is the dynamic viscosity of surroundings that close to the surface of a droplet $\left(\mathrm{m}^{2} / \mathrm{s}\right)$. The total value of heat transferred $\left(Q_{\text {total }}\right)$ from an ejected melt droplet is calculated from Eq (12) [14].

$$
Q_{\text {total }}=m C_{p}\left(T_{2}-T_{1}\right)
$$

where $m$ is the mass of droplet $(\mathrm{kg}), C_{P}$ is the specific heat capacity $\left(\mathrm{J} / \mathrm{kg} .{ }^{\circ} \mathrm{C}\right)$ and $T_{1}$ is the melting temperature of droplet $\left({ }^{\circ} \mathrm{C}\right)$ and $T_{2}$ is the superheat temperature of melt droplet $\left({ }^{\circ} \mathrm{C}\right)$. The time for heat transfer $(\Delta t)$ is calculated from Eq (13) [14].

$$
\Delta t=\frac{Q_{\text {total }}}{Q_{\text {ave }}}
$$

The trajectory of melt droplet was calculated by using Scilab program. The prediction of the distance of melt droplet with different sizes is shown in Fig. 2. It was found that the larger droplets can fly for the longer distance to completely solidify. For example, the melt droplet with a median size of
$106 \mu \mathrm{m}$ requires the maximum distance of $2.5 \mathrm{~m}$ to complete solidification.

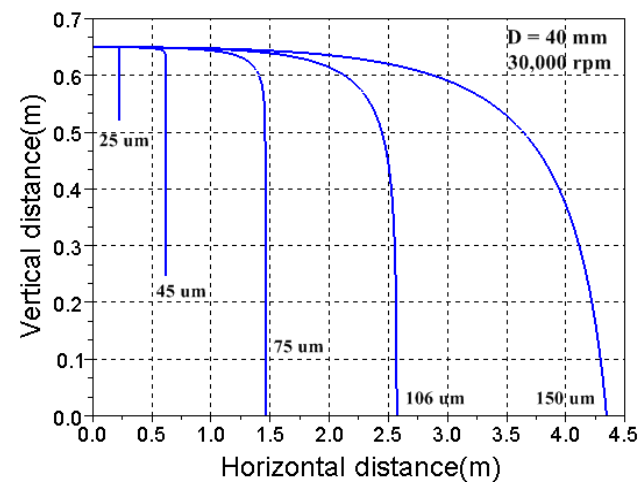

Fig. 2. Theoretical trajectory of melt droplet with different sizes of 25, 45, 75, 106 and $150 \mu \mathrm{m}$, using atomizer disc size, rotational speed of 30,000 rpm, and melt temperature of $40 \mathrm{~mm}, 30,000 \mathrm{rpm}$, and $550{ }^{\circ} \mathrm{C}$, respectively.

\section{EXPERIMENTAL DETAILS}

\section{A. Centrifugal Atomizer}

A centrifugal atomizer as depicted in Fig. 3 was used for the experiment. The atomizer consists of five major components: (1) tundish, (2) atomizer disc, (3) high speed motor, (4) nozzle, and (5) hot air blower. The tundish was set up on the top of the atomizer structure. It was equipped with a silicon carbide crucible surrounded with an electrical heater and connected with $1.5 \mathrm{~mm}$ graphite nozzle (melt flow rate of $50 \mathrm{~kg} / \mathrm{h}$ ) at the bottom of the crucible for delivering melt onto the rotating atomizer disc. A $40 \mathrm{~mm}$ graphite flat disc was used throughout the experiments. The hot air blower was used for preheating the atomizer disc before commencing atomization.

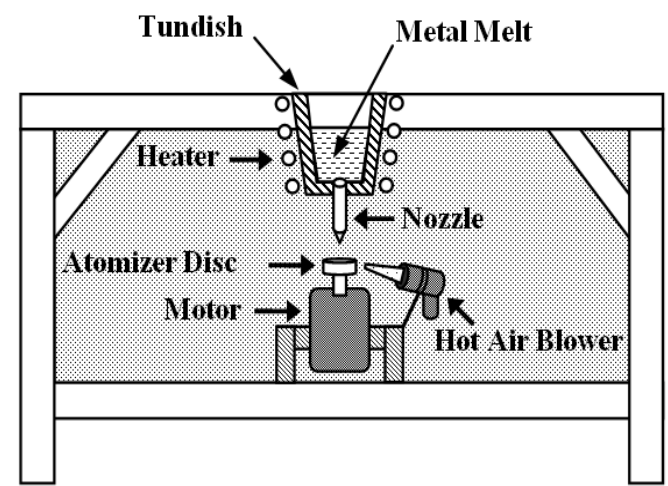

Fig. 3. A schematic diagram of centrifugal atomizer.

\section{B. Material}

Commercial pure zinc metal supplied by Padaeng Industry, Thailand, were used in this study. Chemical composition of zinc metal is given in Table I. The physical properties of molten zinc metal are as follows: density $6,570 \mathrm{~kg} / \mathrm{m}^{3}$, melting temperature $692.5 \mathrm{~K}$, surface tension $0.714 \mathrm{~N} / \mathrm{m}$ and viscosity $0.00408 \mathrm{~Pa} \mathrm{~s}$ [15].

\section{Experiment Procedure}

The experiment was commenced with insertion of zinc ingot into the melting furnace. The zinc ingot was melt at 550 ${ }^{\circ} \mathrm{C}$. After the molten zinc temperature was constant, the atomizer disc was preheated to $300{ }^{\circ} \mathrm{C}$. Prior to atomization 
the high speed motor was turned on and set to a pre-determined rotational speed. Then, the molten zinc metal was transferred and poured into the tundish. The melt was fed through the nozzle onto the rotating atomizer disc to form small droplets and rapidly solidified due to heat convection to the surrounding. The atomizing time was recorded for estimating an average melt flow rate. All experiments were carried out in ambient air atmosphere. After experiment, the atomized zinc powder was collected and analyzed for particle size distribution and median particle size by sieving (ASTM E11). The production yield of atomization was calculated from the percentage of the powders with size smaller than $150 \mu \mathrm{m}$ (those passing through the 100-mesh sieve). The morphology of zinc metal powder in the size range of $-150+45 \mu \mathrm{m}$ was characterized by scanning electron microscopy (SEM Quanta model 400).

TABLEI: CHEMICAL COMPOSITION OF ZINC (WT. \%).

\begin{tabular}{ccccccc}
\hline $\mathrm{Zn}$ & $\mathrm{Pb}$ & $\mathrm{Cd}$ & $\mathrm{Fe}$ & $\mathrm{Cu}$ & $\mathrm{Al}$ & $\mathrm{Sn}$ \\
\hline 99.995 & 0.003 & 0.003 & 0.002 & 0.001 & 0.001 & 0.001 \\
min. & $\max$. & $\max$. & $\max$. & $\max$. & $\max$. & $\max$. \\
\hline
\end{tabular}

\section{RESULT AND DISCUSSION}

\section{A. Effect of Atomizer Disc Speed}

Median particle sizes of the atomized zinc powder are plotted against atomizer disc speeds in Fig. 4. It shows that increasing the angular speed of the atomizer disc shifts the curve toward finer particle size. A higher disc speed exerts more centrifugal force and energy on the liquid metal film spreading on the surface of the disc and consequently finer particles are obtained [16]. This result is consistent to those previously reported by researchers for the atomization of tin [2], magnesium alloy [9], aluminum [17] and lead-free solder alloy [18]. It is noted that there is a deviation of the experimental result from the predictions using Equation 1. This deviation may result from the slippage of melt [2], [17] or it may reflect the time dependent thickness of the oxide film on the melt droplet. Slippage depends on density of melt and wetting of the disc material surface [17]. Fig. 5 shows the production yield versus disc speed. The yield of zinc metal powder increases with increasing speed. Because the production yield in this study was estimated from the amount of zinc powder with size smaller than $150 \mu \mathrm{m}$. As increasing disc speed the finer powders were produced and hence resulted in the higher production yield. The highest production yield of approx. $65 \%$ was achieved at the speed of $30,000 \mathrm{rpm}$.

Fig. 6 shows particle size distribution of zinc metal powders produced by using $40 \mathrm{~mm}$ graphite flat disc at different angular speeds ranging from 10,000 to 30,000 rpm. The curves demonstrate a good linear relation on the log normal distribution plot. The standard deviation of the particle size distribution decreases with increasing atomizer disc speed (Fig.7). At the speed of 15,000 rpm the standard deviation of approx. 1.6 was decreased to approx. 1.45 when the speed was increased to $30,000 \mathrm{rpm}$.

\section{B. Trajectory of Droplet}

The median particle size of zinc powder plotted against the distance from the edge of atomizer disc is shown in Fig. 8. It is evident from the experimental result that the median particle size increases with increasing distance. In other words, the coarser particle can fly to the longer distance than the finer one. Since the larger particle has more mass and resulted in less drag force acting on it (Eq. (6)). This result is consistent to the prediction shown in Fig. 2 and the previous work reported by Halada and Suga [3].

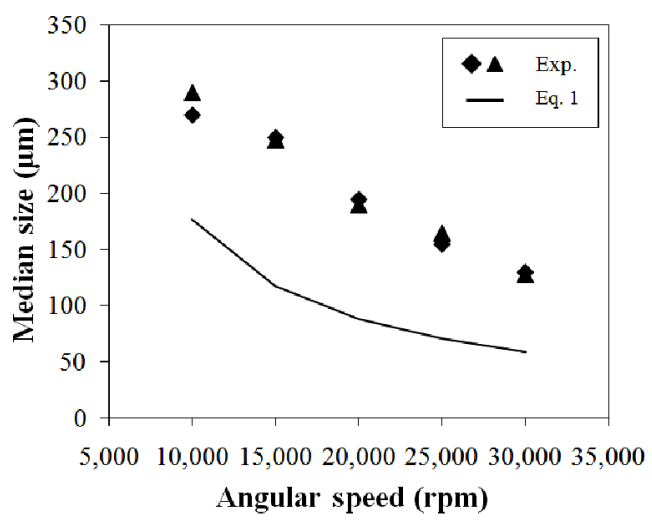

Fig. 4. Effect of disc speed on median particle size.

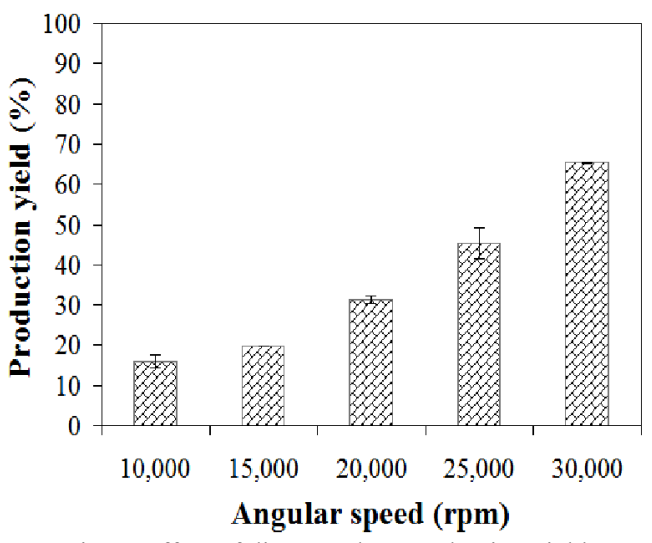

Fig. 5. Effect of disc speed on production yield of zinc metal powder

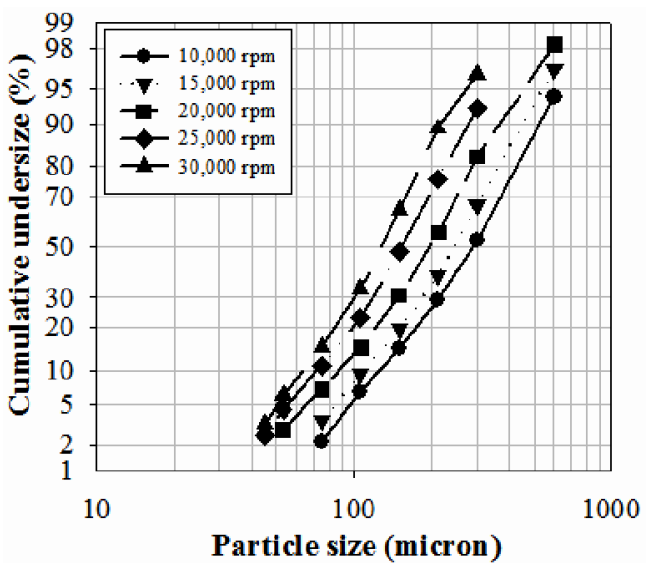

Fig. 6. Log normal plots showing the particle size distribution of zinc metal powder.

\section{Morphology of ZINC Metal Powder}

Fig. 9 shows SEM images of the atomized zinc metal powder for two different sizes, (a) $-53 \mu \mathrm{m}$ and (b) $-150+45$ $\mu \mathrm{m}$. It can be seen that most zinc particles are irregular, elongated flake shape with minor portion of teardrop shape. The irregular shape powder is commonly desired for some particular applications, for example the zinc powder used as a 
friction material for making brake pad in the automotive part manufacturing. The flake shape powder in the present study was obtained by the atomization in air atmosphere. Spherical shape powder was not favored to take place may be due to the oxidation on the surface of the melt droplets. The oxide film would prevent spheroidization of the melt droplets during solidification [17], [18]. Moreover, Angers et al. [9] reported that during centrifugal atomization of AZ91 alloy the irregular particles did not form by an atomization mechanism but by fragmentation of a layer of the atomized melt which solidified at the surface of the rotating disc. This phenomenon could be eliminated by preheating the disc and limiting convection cooling of the disc by the surrounding gas [9]. Previously, it was reported by Halada and Suga [3] that spherical shape powder was produced by centrifugal atomization of molten zinc in the argon gas atmosphere.

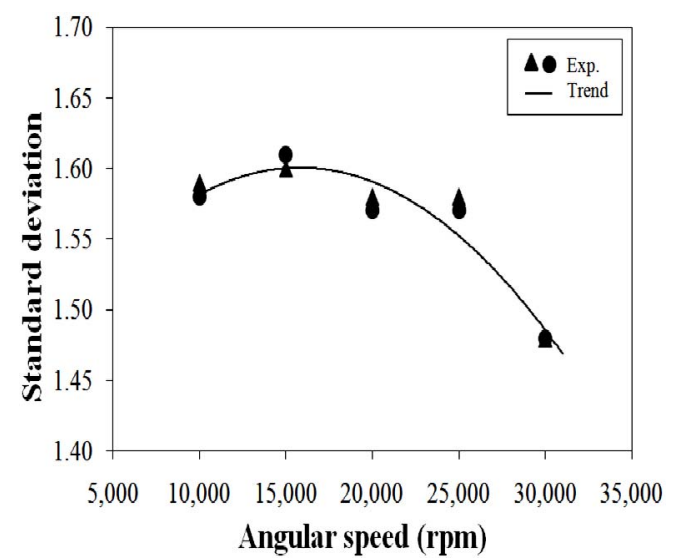

Fig. 7. Effect of disc speed on standard deviation of zinc metal powder.

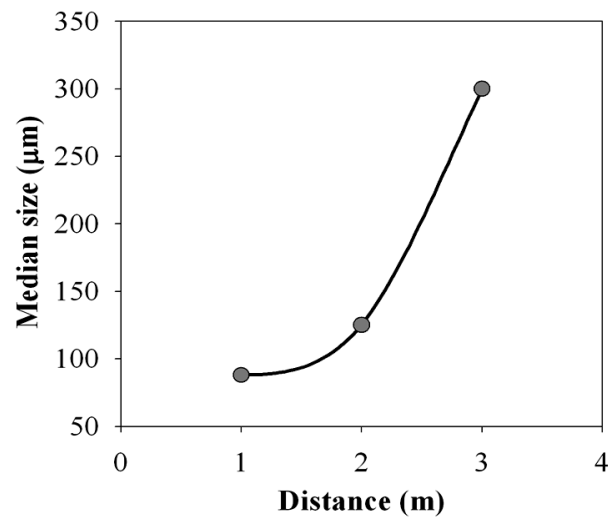

Fig. 8. Median particle size of zinc powder collected at different distances from the edge of atomizer disc.

\section{CONCLUSIONS}

The following conclusions could be drawn from the design calculation and the experimental results:

1. For producing zinc metal powder with median size of $106 \mu \mathrm{m}$, the atomizer chamber should have a minimum radius of $2.5 \mathrm{~m}$ for complete solidification of melt droplets.

2. Median particle size of zinc metal powder was dependent upon the atomizer disc speed. The median particle size decreased with increasing speed.

3. Particle size distribution of zinc metal powder produced by centrifugal atomization demonstrated a good linear relation on the log normal distribution.
The standard deviation of the distribution decreased with increasing atomizer disc speed.

4. Production yield of zinc metal powder increased with increasing atomizer disc speed.

5. Zinc metal powders produced in this study were irregular, elongated flake shape. This type of zinc powder may be suitable for use as a friction material.

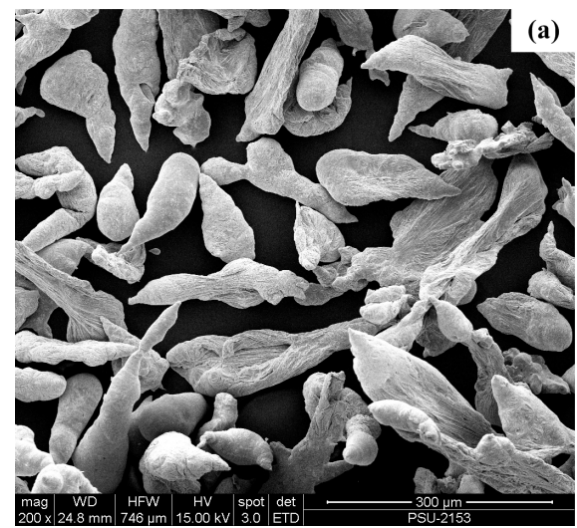

(a)

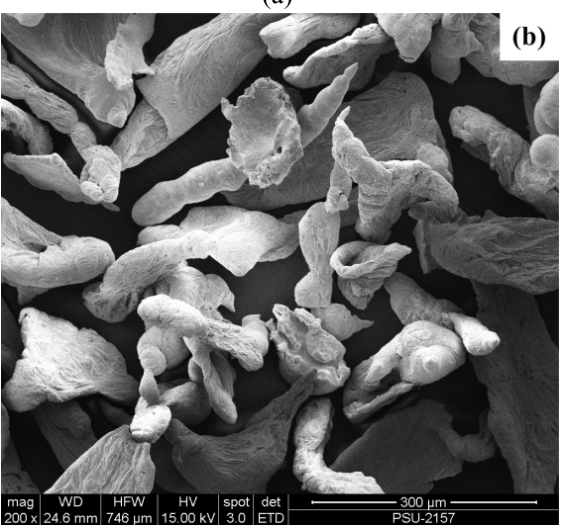

(b)

Fig. 9. SEM micrographs of zinc metal powder, (a) $-53 \mu \mathrm{m}$ and (b) $-150+45$ $\mu \mathrm{m}$.

\section{ACKNOWLEDGMENT}

The authors would like to thank the Department of Mining and Materials Engineering, Faculty of Engineering Prince of Songkla University for the laboratory facilities and the Graduate School, Prince of Songkla University for the financial support.

\section{REFERENCES}

[1] J. J. Dunkley and D. Aderhold, "Centrifugal atomization of metal powders," in Proc. International Conf. Powder Metallurgy and Particulate Materials, Colorado, 2007, pp. 26-31.

[2] J. W. Xie, Y. Y. Zhou, and J. J. Dunkley, "Effect of processing conditions on powder particle size and morphology in centrifugal atomization of tin," Powder. Metall., vol. 47, pp. 168-172, Mar. 2004.

[3] K. Halada and H. Suga, "Study on parameters for centrifugal atomization with atomizing molten zinc," J. Jpn. Soc. Powder Powder Metall., vol. 37, pp. 398-404, Mar. 1990.

[4] A. J. Yule and J. J. Dunkley, Atomization of Metals for Powder Production and Spray Depositoin, Clarendon Press, Oxford, UK, 1994, pp. 223-224.

[5] ASL. (October 1998). Zinc powder. Atomizing news. [Online]. pp. 29-32. Available: http://www.atomising.co.uk/news.html

[6] Handbook of Non-Ferrous Metal Powders Technologies and Applications, Elsevier, Oxford, 2009, pp. 409-420. 
[7] GRACO, INC. (May 1995). Atomization. Concept and theory training. [Online]. pp. 1-14. Available: http://www.elliottequipment.com/ask/

[8] Y. Yue, J. W. Sutherland, and W. W. Olson, "Cutting fluid mist formation in machining via atomization mechanisms," Presented at International Mechanical Engineering Congress and Exposition, Atlanta, Georgia, November 17-22, 1996.

[9] R. Angers, R. Tremblay, and D. Dube, "Formation of irregular particles during centrifugal atomization of AZ91 alloy," Mater. Lett., vol. 33, pp. 13-18, Nov. 1997.

[10] Y. Y. Zhou, "Considerations in designing a centrifugal atomizer for metal powder product," Mater. Design, vol. 27, pp. 745-750, Feb. 2006.

[11] W. L. Falke, A. E. Schwaneke, and R. W. Nash, "Surface tension of zinc: the positive temperature coefficient," Metall. Trans. B, vol. 8 , pp. 301-303, Jun. 1997.

[12] E. Teunou and D. Poncelet, "Rotary disc atomization for microencapsulation application prediction of the particle trajectories," J. Food. Eng., vol. 71, pp. 345-353, Dec. 2005.

[13] B. R. Munson, D. F. Young and T. H. Okiishi, Fundamentals of Fluid Mechanics, 5th ed. John Wiley and Sons, Inc, 2005, ch. 8, pp. 614-683.

[14] Y. A. Cengle, Heat Transfer, A Practical Approach, 3nd ed. McGraw-Hill, Singapore, 2004, pp. 367-418.

[15] M. R. Hopkins and T. C. Toye, "The determination of the viscosity of molten metals," in Proc. Phys. Soc. B63Conf., 1950, pp.773-782.

[16] S. Ozturk, F. Arslan and B. Ozturk, "Effect of process parameters on production of metal powders by water jet cooled rotating disc atomization," Powder Metall., vol. 48, pp. 163-170, Jun. 2005.

[17] S.M. Shikhaliev, Z. I. Shikhalieva, and J. J. Dunkley, "Spin atomization makes tighter safer aluminium," Metal Powder Report, vol. 63 , pp. 28-30, Feb. 2008

[18] T. Plookphol, S. Wisutmethangoon, and S. Gonsrang, "Influence of process parameters on SAC305 lead-free solder powder produced by centrifugal atomization," Powder Tech., vol. 214, pp. 506-512, Dec. 2011

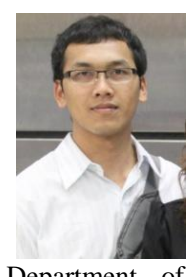

Phairote Sungkhaphaitoon was born in Nakhon Si Thammarat, Thailand on December 1, 1985. He holds B.S. in Materials Science from the Faculty of Science, Prince of Songkla University, Hat Yai, Thailand and M.Eng. in Materials Engineering from the Faculty of Engineering, Prince of Songkla University, Hat Yai, Thailand. Mr. Phairote Sungkhaphaitoon is now a Ph.D. candidate in the Department of Mining and Materials Engineering, Faculty of Engineering, Prince of Songkla University, Hat Yai, Thailand. His research interests are mainly focused on the metal powder processing by atomization techniques.

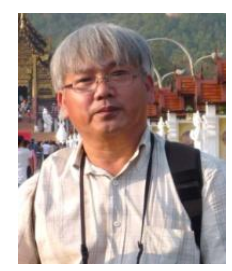

Thawatchai Plookphol was born in Phuket, Thailand on September 24, 1958. He holds B.S in Mining and Metallurgical Engineering from Prince of Songkla University, Hat Yai, Thailand, M.Eng. in Geotechnical Engineering from Asian Institute of Technology, Thailand, M.S. and $\mathrm{Ph.D}$. in Metallurgical Engineering from the University of Wisconsin-Madison, U.S.A. Dr. Thawatchai Plookphol is now an assistant professor in the Department of Mining and Materials Engineering, Faculty of Engineering, Prince of Songkla University, Hat Yai, Thailand. His research interests are mechanical behavior of materials, creep, lead-free soldering alloys and powder metallurgy.

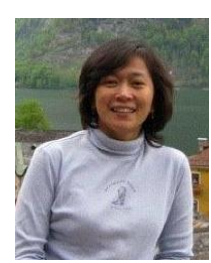

Sirikul Wisutmethangoon was born in Phuket, Thailand on October 7, 1966. She holds B.Eng. in Mechanical Engineering from Prince of Songkla University, Hat Yai, Thailand, M.S. and Ph.D.in Metallurgical Engineering from the University of Wisconsin-Madison, U.S.A. Dr. Sirikul Wisutmethangoon is now an associate professor in the Department of Mechanical Engineering, Faculty of Engineering, Prince of Songkla University. Her research interests are materials characterization, physical metallurgy, heat treatment and powder metallurgy. 